\title{
Extracorporeal cytokine adsorption in septic shock: A proof of concept randomized, controlled pilot study
}

\author{
Fatime Hawchar ${ }^{\mathrm{a}}$, Ildikó László a ${ }^{\mathrm{a}}$, Nándor Öveges ${ }^{\mathrm{a}}$, Domonkos Trásy ${ }^{\mathrm{a}}$, Zoltán Ondrik ${ }^{\mathrm{b}}$, Zsolt Molnar ${ }^{\mathrm{a}, *}$ \\ ${ }^{a}$ University of Szeged, Department of Anaesthesiology and Intensive Therapy, Szeged H-6725, 6. Semmelweis utca, Hungary \\ b University of Szeged, Department of Nephrology, H-6720 Szeged, Korányi fasor 8-10, Hungary
}

\section{A R T I C L E I N F O}

\section{Keywords:}

Septic shock

Cytokine storm

Extracorporeal blood purification

Cytokine removal

CytoSorb

Hemoadsorption

\begin{abstract}
A B S T R A C T
Background: The aim of this proof of concept, prospective, randomized pilot trial was to investigate the effects of extracorporeal cytokine removal (CytoSorb $\AA$ ) applied as a standalone treatment in patients with septic shock. Methods: 20 patients with early $(<24 \mathrm{~h})$ onset of septic shock of medical origin, on mechanical ventilation, norepinephrine $>10 \mu \mathrm{g} / \mathrm{min}$, procalcitonin $(\mathrm{PCT})>3 \mathrm{ng} / \mathrm{mL}$ without the need for renal replacement therapy were randomized into CytoSorb $(n=10)$ and Control groups $(n=10)$. CytoSorb therapy lasted for $24 \mathrm{~h}$. Clinical and laboratory data were recorded at baseline $\left(\mathrm{T}_{0}\right), \mathrm{T}_{12}, \mathrm{~T}_{24}$, and $\mathrm{T}_{48}$ hours.

Results: Overall SOFA scores did not differ between the groups. In the CytoSorb-group norepinephrine requirements and PCT concentration decreased significantly (norepinephrine: CytoSorb: $\mathrm{T}_{0}=0.54[\mathrm{IQR}: 0.20-1.22]$, $\mathrm{T}_{48}=0.16[\mathrm{IQR}: 0.07-0.48], p=.016 ;$ Controls: $\mathrm{T}_{0}=0.43[\mathrm{IQR}: 0.19-0.64], \mathrm{T}_{48}=0.25[\mathrm{IQR}: 0.08-0.65] \mu \mathrm{g} / \mathrm{kg} / \mathrm{min}$; PCT: CytoSorb: $\mathrm{T}_{0}$ median $=20.6[\mathrm{IQR}: 6.5-144.5], \mathrm{T}_{48}=5.6[1.9-54.4], p=.004 ;$ Control: $\mathrm{T}_{0}=13.2[7.6-47.8]$, $\left.\mathrm{T}_{48}=9.2[3.8-44.2] \mathrm{ng} / \mathrm{mL}\right)$. Big-endothelin-1 concentrations were also significantly lower in the CytoSorb group (CytoSorb: $\mathrm{T}_{0}=1.3 \pm 0.6,{ }^{*} \mathrm{~T}_{24}=1.0 \pm 0.4, \mathrm{~T}_{48}=1.4 \pm 0.8,{ }^{*} p=.003 ;$ Control: $\mathrm{T}_{0}=1.1 \pm 0.7, \mathrm{~T}_{24}=$ $\left.1.1 \pm 0.6, \mathrm{~T}_{48}=1.2 \pm 0.6 \mathrm{pmol} / \mathrm{L}, p=.115\right)$. There were no CytoSorb therapy-related adverse events.

Conclusions: This is the first trial to investigate the effects of early extracorporeal cytokine adsorption treatment in septic shock applied without renal replacement therapy. It was found to be safe with significant effects on norepinephrine requirements, PCT and Big-endothelin- 1 concentrations compared to controls.

Trial registration: The study has been registered on ClinicalTrials.gov, under the registration number of NCT02288975, registered 13 November 2014.
\end{abstract}

(c) 2018 Elsevier Inc. All rights reserved.

\section{Background}

Sepsis and septic shock is a devastating condition with mortality rates between 20 and 50\% [1-3]. The pathophysiology of sepsis is remarkably complex, which explains the heterogeneous, often

Abbreviations: AIDS, Acquired Immune Deficiency Syndrome; APACHE II, Acute Physiology and Chronic Health Evaluation; BigET-1, Big endothelin-1; $\beta$-HCG, $\beta$-Human Chorionic Gonadotropin; CI, Cardiac Index; CRP, C-reactive Protein; ECG, Electrocardiography; EVLWI, Extravascular Lung Water Index; HIV, Human Immunodeficiency Virus; HR, Heart Rate; ICU, Intensive Care Unit; IL, Interleukin; MAP, Mean Arterial Pressure; $\mathrm{PaO}_{2} / \mathrm{FiO}_{2}$, arterial oxygen tension/fractional inspired oxygen; $\mathrm{pCO}_{2}$-gap, Central venous to arterial $\mathrm{CO}_{2}$-gap; PCT, Procalcitonin; PiCCO, Pulse Contour Cardiac Output; PPV, Pulse Pressure Volume; $\mathrm{ScvO}_{2}$, Central venous oxygen saturation; SOFA, Sequential Organ Failure Assessment Score; SVRI, Systemic Vascular Resistance Index.

* Corresponding author.

E-mail addresses: hawchar.fatime@med.u-szeged.hu (F. Hawchar),

laszlo.ildiko@med.u-szeged.hu (I. László), oveges.nandor.jozsef@med.u-szeged.hu (N. Öveges), trasy.domonkos@med.u-szeged.hu (D. Trásy), office.aiti@med.u-szeged.hu (Z. Ondrik), office.aiti@med.u-szeged.hu (Z. Molnar). unpredictable clinical appearance of this condition [4,5]. The process begins with the host's immune response triggered by various insults [6]. In sepsis, this response to an infectious insult becomes dysregulated, and cytokines, chemokines and other inflammatory regulators are released leading to an imbalance between the pro-, and anti-inflammatory forces. This condition is also referred to as a 'cytokine storm' [7]. The hypothesis that a cytokine storm may be responsible for the observed self-destructive sequence of events in sepsis forms the pathophysiological rationale of mass removal of circulating cytokines [8,9].

When basic therapeutic measures, such as early adequate resuscitation, source control and organ support fail to improve the patients' condition, additional therapeutic alternatives, called 'adjuvant therapies', are sometimes considered in order to improve outcome [9]. The most frequently investigated adjuvant therapies are: immunoglobulintherapy, endotoxin-binding Polymyxin B hemoperfusion, and high-capacity continuous blood-, and plasma filtration [10-12]. One of the recent adjuvant alternatives is extracorporeal cytokine adsorption with a device called CytoSorb ${ }^{\circledR}$ (CytoSorbents Corporation, New Jersey, USA) that became available in clinical practice in 2011. This is a high- 
flow, low-resistance cytokine adsorbent, containing specially developed polymer beads with a huge adsorption surface and adsorption spectrum between 5 and $60 \mathrm{kDa}[13]$.

There are over 100 case studies that describe the use of extracorporeal cytokine adsorption in many clinical scenarios, and in general, the effects are promising and the treatment well tolerated. With regard to the treatment of sepsis, clinical trials are lacking at present, and what we have are mainly small case series [14-17]. There is also an international CytoSorb Registry, and recent data analysis on 198 patients indicate that observed mortality (65\%) was substantially better compared to predicted (mean of $81 \%$ ), and treatment was also shown to be safe [18].

However, the treatment has mainly been used together with renal replacement therapy and no study has tested its effect when applied as an adjuvant therapy on its own.

Therefore, the aim of this prospective, randomized, controlled, proof of concept (i.e.: testing it as a standalone extracorporeal treatment without the need of renal replacement therapy), pilot study was to investigate the effects of early (started within $24 \mathrm{~h}$ after ICU administration), 24-h long cytokine-adsorption therapy on organ dysfunction and inflammatory response in patients with septic shock, and to provide further data on safety.

\section{Materials and methods}

\subsection{Patients}

All patients with septic shock of medical origin were screened for suitability for the study from January 2015 to December 2017 on a level III, 36 bedded multidisciplinary intensive care unit (ICU) in our university hospital. The inclusion and exclusion criteria were the following.

Inclusion criteria: Intubated, mechanically ventilated patients with suspected septic shock of medical origin; invasive hemodynamic monitoring guided demand for norepinephrine $>10 \mu \mathrm{g} / \mathrm{min}$; elevated lactate concentrations $>2.0 \mathrm{mmol} / \mathrm{L}$; and a procalcitonin (PCT) concentration $\geq 3 \mathrm{ng} / \mathrm{mL}$ were considered candidates for the study. Inclusion had to take place after the first $6 \mathrm{~h}$ at least of resuscitation and antibiotic therapy, when there was no improvement as indicated by steady or increased norepinephrine requirements, and study treatment should be commenced within the first $24 \mathrm{~h}$ after ICU admission or the onset of septic shock.

\subsection{Exclusion criteria}

Patients under 18 years of age; acute or chronic renal insufficiency requiring renal replacement therapy; pregnancy ( $\beta$-hCG test positivity); operation in connection with the septic condition of the patient; end-stage cardiomyopathy; acute coronary syndrome; cardiogenic shock; hemato-oncological diseases; admission after cardiac arrest; immune-compromised patients due to HIV positivity and active AIDS or organ transplantation or on chronic steroid treatment ( $>10 \mathrm{mg} /$ day prednisolone); thrombocytopenia $(<20 \mathrm{G} / \mathrm{L})$; other coagulopathies contraindicating extracorporeal therapies.

\section{Randomization and interventions}

Patients who fulfilled the entry criteria were randomized into CytoSorb or Control groups by sealed envelope block randomization (blocks of 10). Randomized envelopes were numbered and were opened one by one when including a patient. Random allocation sequence was created by IL. Randomization and patient enrolment was performed by FH, IL, NÖ and DT. Patients in both groups received standard treatment according to the institutional adaptation of the Surviving Sepsis Guidelines [19]. In addition to routine monitoring (such as 5-lead ECG, pulse oximetry, invasive arterial blood pressure measurement, hourly diuresis, temperature, end-tidal $\mathrm{CO}_{2}$, airway pressures, etc.), invasive hemodynamic monitoring by using the PiCCO technology (PiCCO, PULSION-Maquet, Germany) was also applied and hemodynamic management was guided accordingly. The main parameters assessed were: cardiac index $(C I)$, pulse pressure variation (PPV), systemic vascular resistance index (SVRI) and extravascular lung water index (ELWI).

Patients in the CytoSorb group received a hemodialysis catheter inserted into a central vein (femoral, subclavian or internal jugular, as appropriate). Treatment was performed as instructed by the company's user guide. In short, CytoSorb was placed in a blood pump circuit using a renal replacement device (MultiFiltrate, Fresenius Medical Care, Bad Homburg von der Höhe, Germany), with heparin anticoagulation and a blood flow rate of $250-400 \mathrm{~mL} / \mathrm{min}$.

\section{Measurements}

First measurements $\left(\mathrm{T}_{0}\right)$ were performed right after inclusion (Control group) or after the start of extracorporeal cytokine adsorption therapy, then 12, 24 and $48 \mathrm{~h}$ later $\left(\mathrm{T}_{12}, \mathrm{~T}_{24}, \mathrm{~T}_{48}\right)$. At these time points blood samples were drawn and complete hemodynamic measurements as well as arterial and central venous blood gas analysis and determination of inflammation marker concentrations were performed. Serum PCT, CRP and bigendothelin-1 (BigET-1) were determined by the hospital's central laboratory. Sequential (Sepsis-related) Organ Failure Assessment (SOFA) scores were calculated to monitor organ dysfunction [20].

\section{Safety}

Potentially, complications may be similar to that of any extracorporeal technique: related to central vein cannulation or bleeding due to anticoagulation, but the extracorporeal cytokine adsorption therapy itself may also provoke an unexpected allergic response, or other effects which may affect organ function. In order to assess safety, regular analysis of clotting, and organ function were assessed.

\section{Statistical analysis}

As this was meant to be a proof of concept pilot study, investigating the safety and potential clinical effects of the treatment, the original idea was to include 20 patients ( 10 in each group). Power calculation was not performed due to the lack of similarly designed studies in the literature at the time when the study protocol was written. In fact, the aim of this study was to provide data for power calculations for future studies (hence the proof of concept, pilot fashion), to investigate certain clinical effects as the primary outcome but not mortality, as the latter would have required far higher patient numbers.

Data were primarily recorded in Microsoft Excel 2016. Data were analyzed using IBM SPSS 23.0 (Armonk, NY, USA) and Systat Software Inc. SigmaPlot 12.5 (London, UK). Shapiro-Wilk test was used to test normality. In case of demographic data, Student t-test or MannWhitney $U$ test was applied. Analysis of variance (ANOVA) with Bonferroni post hoc test was used to compare the groups. The level of significance was defined as $p<.05$.

\section{Results}

Patients were included between January 2015 until December 2017. All patients with suspected septic shock were screened for eligibility (Fig. 1). From the relatives of those who fulfilled the inclusion criteria written informed consent was obtained before the study. In 3 cases we could not obtain consent, hence we extended the study to recruit 3 more patients (hence the total of 23) to reach the target of 10 per group. 


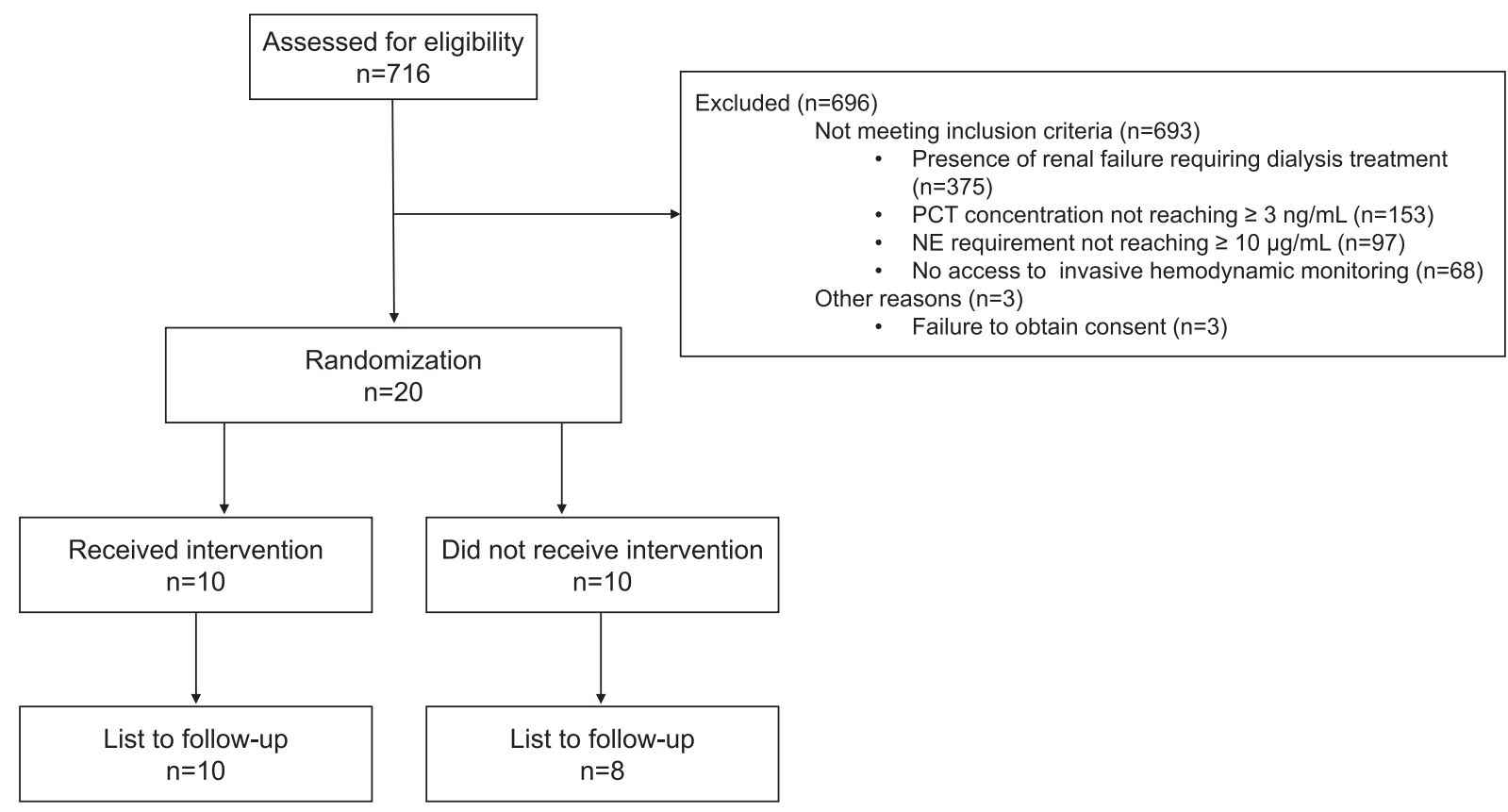

Fig. 1. Flowchart of patient screening and involvement according to CONSORT.

\subsection{Demography}

Patients' demographic data are summarized in Table 1. There was no significant difference between CytoSorb and Control groups regarding age, body mass index, days spent on the ICU and APACHE II scores. All patients survived the first day of the study. All patients survived the study period of $48 \mathrm{~h}$ in the CytoSorb group, but 2 patients died in the Control group just before the 48th hour time period, hence in these 2 cases the last available measurements were used for analysis, otherwise ICU mortality was similar.

\subsection{SOFA scores}

The SOFA scores in the CytoSorb group $\left(\mathrm{T}_{0}=13.6 \pm 3.2 ; \mathrm{T}_{12}=13.1\right.$ $\pm 3.6 ; \mathrm{T}_{24}=13 \pm 5.4 ; \mathrm{T}_{48}=11.6 \pm 6.3$ ) did not differ significantly from the Control group $\left(\mathrm{T}_{0}=12.8 \pm 3.9 ; \mathrm{T}_{12}=12.9 \pm 5.0 ; \mathrm{T}_{24}=12.6 \pm 5.9\right.$; $\left.\mathrm{T}_{48}=11.0 \pm 6.3\right)$.

\subsection{Hemodynamic parameters}

Results of the hemodynamic measurements are shown in Table 2. There were no significant differences either within, or between the groups as far as mean arterial pressure (MAP), heart rate (HR), cardiac index $(\mathrm{CI})$ and pulse pressure variability (PPV) were concerned.
Extravascular lung water index (ELWI) was higher in the CytoSorb group and showed decreasing tendencies in both groups, but these differences did not reach statistical significance. Systemic vascular resistance (SVRI) decreased gradually in the Control group until $\mathrm{T}_{24}$, while it showed an increasing tendency in the CytoSorb group during treatment, although this did not prove to be significant. Patients in the CytoSorb group required almost twice the norepinephrine dose on entering the study as Controls, a difference that was not significant, but there was a significant decrease in this group (by almost $70 \%$ compared to baseline), which was not observed in the Control group (Fig. 2). Patients received similar amount of fluid replacement over the study period.

\subsection{Blood gas parameters}

Lactate concentrations were elevated initially and decreased in both groups (Table 2). Central venous to arterial $\mathrm{CO}_{2}$-gap ( $\mathrm{pCO}_{2}$-gap) changed in opposite directions: decreasing in the CytoSorb and increasing in the Control group, but these changes did not achieve statistical significance. Similar values of $\mathrm{ScvO}_{2}$ were observed in both groups.

Oxygenation, as indicated by $\mathrm{PaO}_{2} / \mathrm{FiO}_{2}$, were lower in the CytoSorb group and showed improvement by $\mathrm{T}_{48}$, which remained more or less unchanged in the Control group, although these changes remained non-significant.

Table 1

Demographic data.

\begin{tabular}{|c|c|c|c|}
\hline Parameters & All & CytoSorb & Control \\
\hline $\mathrm{N}$ (male/female) & $20(13 / 7)$ & $10(7 / 3)$ & $10(6 / 4)$ \\
\hline Age (years) & $65.6 \pm 12.9$ & $60 \pm 10$ & $71 \pm 14$ \\
\hline Body Mass Index & $28.8 \pm 8.0$ & $30.5 \pm 10.2$ & $26.9 \pm 4.4$ \\
\hline ICU length of stay (days) & $10.1 \pm 6.5$ & $10.2 \pm 8.5$ & $10.0 \pm 4.3$ \\
\hline APACHE II & $28 \pm 7$ & $26 \pm 9$ & $30 \pm 6$ \\
\hline Mortality within $48 \mathrm{~h}$ & 2 & 0 & 2 \\
\hline Etiology $(\mathrm{n})$ & - & $\begin{array}{l}\text { Pneumonia ( } 7 \text { ) } \\
\text { pancreatitis (1) } \\
\text { toxic shock syndrome (1) } \\
\text { urosepsis (1) }\end{array}$ & $\begin{array}{l}\text { Pneumonia (6) } \\
\text { meningococcus sepsis (2) } \\
\text { cholangiosepsis (1) } \\
\text { dermatomyositis (1) }\end{array}$ \\
\hline Number of dialysis treatments & 47 & $2.6 \pm 1.5$ & $2.1 \pm 4.3$ \\
\hline
\end{tabular}

N: number of subjects, ICU: Intensive Care Unit, APACHE II: Acute Physiology and Chronic Health Evaluation II score. Data are presented as mean \pm standard deviation. 
Table 2

Hemodynamic and laboratory parameters.

\begin{tabular}{|c|c|c|c|c|c|}
\hline & Group & $\mathrm{T}_{0}$ & $\mathrm{~T}_{12}$ & $\mathrm{~T}_{24}$ & $\mathrm{~T}_{48}$ \\
\hline \multirow[t]{2}{*}{ MAP (mmHg) } & CytoSorb & $80 \pm 10$ & $74 \pm 9$ & $76 \pm 9$ & $81 \pm 15$ \\
\hline & Control & $83 \pm 8$ & $82 \pm 8$ & $79 \pm 10$ & $84 \pm 10$ \\
\hline \multirow{2}{*}{$\operatorname{HR}(1 / \min )$} & CytoSorb & $69 \pm 12$ & $69 \pm 26$ & $73 \pm 28$ & $59 \pm 14$ \\
\hline & Control & $62 \pm 13$ & $76 \pm 24$ & $67 \pm 12$ & $71 \pm 12$ \\
\hline \multirow[t]{2}{*}{$\mathrm{CI}\left(1 / \mathrm{min} / \mathrm{m}^{2}\right)$} & CytoSorb & $3.2 \pm 1.1$ & $3.1 \pm 1.2$ & $3.2 \pm 1.5$ & $3.4 \pm 1.1$ \\
\hline & Control & $3.0 \pm 0.8$ & $3.8 \pm 0.5$ & $3.8 \pm 0.7$ & $3.5 \pm 0.9$ \\
\hline \multirow[t]{2}{*}{ PPV (\%) } & CytoSorb & $12.2 \pm 5.3$ & $14.9 \pm 6.1$ & $12.1 \pm 6.2$ & $12.6 \pm 5.6$ \\
\hline & Control & $11.8 \pm 5.7$ & $13.9 \pm 7.4$ & $12.1 \pm 6.9$ & $13.7 \pm 4.9$ \\
\hline \multirow{2}{*}{ EVLWI (mL/kg) } & CytoSorb & $16.4 \pm 10.1$ & $14.6 \pm 6.0$ & $13.6 \pm 6.1$ & $13.1 \pm 5.0$ \\
\hline & Control & $8.7 \pm 3.7$ & $7.8 \pm 2.5$ & $7.8 \pm 3.0$ & $7.1 \pm 1.7$ \\
\hline SVRI & CytoSorb & $1909 \pm 497$ & $2030 \pm 755$ & $1946 \pm 598$ & $1806 \pm 494$ \\
\hline$\left(\right.$ dyn $\left.\times \mathrm{s} / \mathrm{cm}^{5} / \mathrm{m}^{2}\right)$ & Control & $2314 \pm 812$ & $1656 \pm 252$ & $1588 \pm 300$ & $1852 \pm 377$ \\
\hline \multirow[t]{2}{*}{ Cumulative total i.v. fluid $(\mathrm{mL})$} & CytoSorb & - & $2195.8 \pm 1319.0$ & $3922.1 \pm 1634.2$ & $6861.6 \pm 1488.3$ \\
\hline & Control & - & $2370.3 \pm 816.6$ & $4639.2 \pm 2477.1$ & $7648.3 \pm 2988.3$ \\
\hline \multirow{2}{*}{ Lactate (mmol/L) } & CytoSorb & $3.6 \pm 3.9$ & $4.4 \pm 4.7$ & $3.1 \pm 3.3$ & $2.4 \pm 2.9$ \\
\hline & Control & $3.0 \pm 2.4$ & $2.1 \pm 1.2$ & $1.6 \pm 0.7$ & $1.4 \pm 0.5$ \\
\hline \multirow[t]{2}{*}{$\mathrm{CO}_{2}$ gap $(\mathrm{mmHg})$} & CytoSorb & $7.8 \pm 3.5$ & $7.0 \pm 3.4$ & $6.1 \pm 3.6$ & $4.1 \pm 4.7$ \\
\hline & Control & $2.8 \pm 5.4$ & $4.8 \pm 2.8$ & $4.7 \pm 1.8$ & $6.6 \pm 1.6$ \\
\hline \multirow[t]{2}{*}{$\mathrm{ScvO}_{2}(\%)$} & CytoSorb & $75.8 \pm 9.6$ & $78.4 \pm 8.2$ & $76.3 \pm 5.4$ & $77.9 \pm 5.0$ \\
\hline & Control & $80.9 \pm 5.7$ & $82.1 \pm 4.2$ & $81.1 \pm 3.5$ & $78.2 \pm 6.0$ \\
\hline \multirow{2}{*}{$\begin{array}{l}\mathrm{PaO}_{2} / \mathrm{FiO}_{2} \\
(\mathrm{mmHg})\end{array}$} & CytoSorb & $173.2 \pm 64.2$ & $212.7 \pm 99.2$ & $293.9 \pm 207.1$ & $243.9 \pm 116.8$ \\
\hline & Control & $249.5 \pm 127.6$ & $215.5 \pm 81.0$ & $227.5 \pm 100.4$ & $244.0 \pm 83.0$ \\
\hline \multirow[t]{2}{*}{ CRP $(\mathrm{mg} / \mathrm{L})$} & CytoSorb & $238.1 \pm 95.5$ & $226.8 \pm 109.2$ & $220.3 \pm 104.0$ & $169.54 \pm 86.4$ \\
\hline & Control & $307.4 \pm 116.7$ & $307.7 \pm 104.2$ & $280.4 \pm 80.8$ & $189.9 \pm 48.5$ \\
\hline \multirow[t]{2}{*}{ BigET-1 (pmol/L) } & CytoSorb & $1.3 \pm 0.6$ & $0.9 \pm 0.3 \#$ & $1.0 \pm 0.4 \#$ & $1.4 \pm 0.8$ \\
\hline & Control & $1.1 \pm 0.7$ & $1.0 \pm 0.5$ & $1.1 \pm 0.6$ & $1.2 \pm 0.6$ \\
\hline \multirow[t]{2}{*}{$\mathrm{eGFR}\left(\mathrm{mL} / \mathrm{min} / \mathrm{m}^{2}\right)$} & CytoSorb & $31.0 \pm 19.4$ & $30.0 \pm 14.9$ & $35.3 \pm 19.5$ & $34.0 \pm 21.6$ \\
\hline & Control & $41.3 \pm 15.7$ & $40.6 \pm 19.2$ & $44.9 \pm 25.6$ & $45.4 \pm 26.3$ \\
\hline \multirow[t]{2}{*}{ Creatinine $(\mu \mathrm{mol} / \mathrm{L})$} & CytoSorb & $215.7 \pm 187.5$ & $181.5 \pm 124.6$ & $164.3 \pm 123.68$ & $177.1 \pm 166.0$ \\
\hline & Control & $141.4 \pm 87.9$ & $181.8 \pm 105.1$ & $186.3 \pm 158.7$ & $147.6 \pm 138.8$ \\
\hline \multirow[t]{2}{*}{ Fluid balance (mL/24 h) } & CytoSorb & - & $1454.7 \pm 1382.2$ & $1089.6 \pm 861.1$ & $1475.1 \pm 1262.7$ \\
\hline & Control & - & $1210.2 \pm 940.8$ & $1239.1 \pm 1829.6$ & $1166.7 \pm 1258.3$ \\
\hline
\end{tabular}

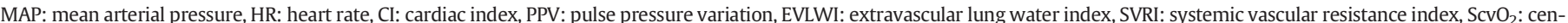

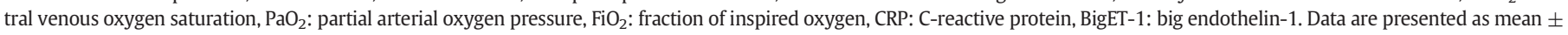
standard deviation; \#: $\mathrm{p}<.05$ vs. $\mathrm{T}_{0}$.

\subsection{Biomarkers}

Regarding CRP concentration, the CytoSorb and Control groups did not differ significantly and both groups showed a decrease by $\mathrm{T}_{48}$ (Table 2).

Regarding PCT (Fig. 3), there was a significant decrease in both groups, however, the kinetics were different. In the Control group, a
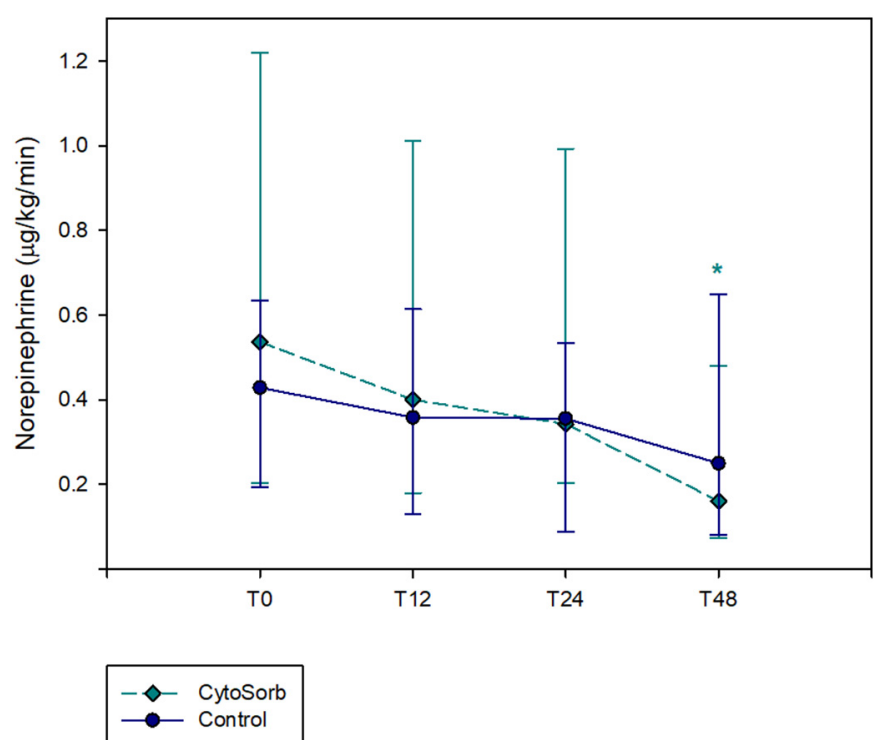

Fig. 2. Kinetics of norepinephrine need in the CytoSorb and in the Control group. Data are shown as median and interquartile ranges. ${ }^{*} p<.05$ vs. $\mathrm{T}_{0}$ significant drop in PCT was detected at $\mathrm{T}_{48}\left(p=.04 \mathrm{vs}\right.$. $\left.\mathrm{T}_{0}\right)$, while in the CytoSorb group this decrease was more pronounced and was already significant at $\mathrm{T}_{24}$ and also at $\mathrm{T}_{48}$.

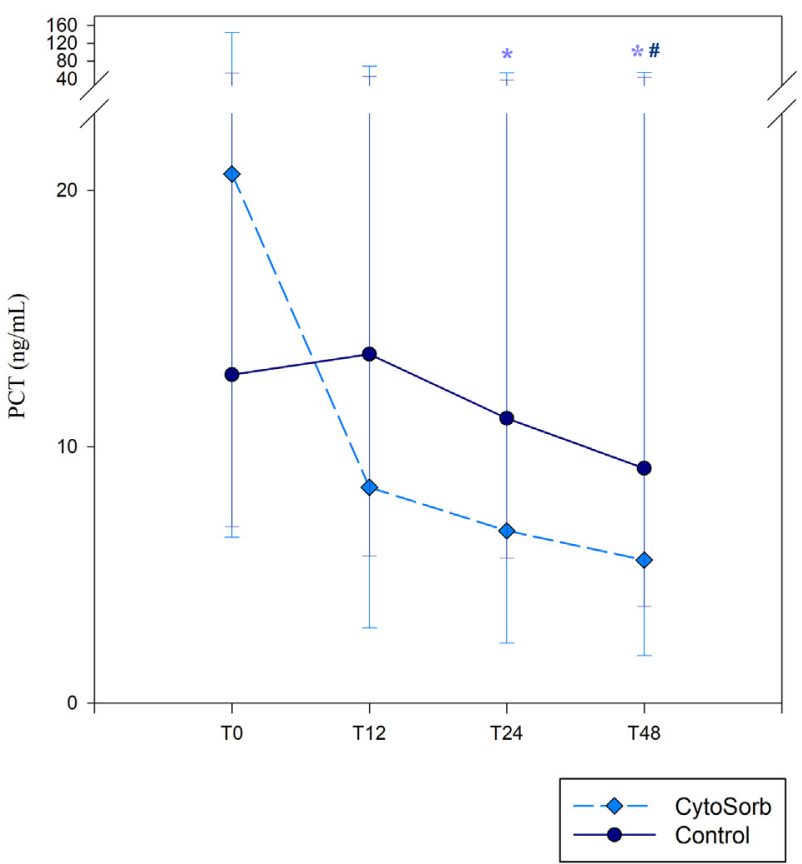

Fig. 3. Procalcitonin kinetics in the CytoSorb and in the Control group. Data are presented as median and interquartile ranges. ${ }^{*} \mathrm{p}<.05 \mathrm{vs}$. $\mathrm{T}_{0 \text { CytoSorb }}, \# \mathrm{p}<.05 \mathrm{vs}$. $\mathrm{T}_{0 \text { Control. }}$ 
BigET-1 was significantly decreased in the CytoSorb group by $\mathrm{T}_{12}$ and $\mathrm{T}_{24}$ as compared to baseline, and remained almost unchanged in the Control group (Table 2).

\subsection{Adverse effects}

Finally, we did not observe any adverse effects due to extracorporeal cytokine adsorption therapy.

\section{Discussion}

This proof of concept pilot study found that adjunctive therapy with standalone extracorporeal cytokine removal for $24 \mathrm{~h}$ during the early phase of therapy-resistant septic shock proved to be safe and also resulted some significant effects compared to the control group.

\subsection{Clinical effects}

In the current study, we did not observe any intervention related adverse events, hence 24-h adsorption therapy proved to be safe which is in accord with previously reported case series and clinical studies [21-24].

Though there were no significant differences in the SOFA scores between the groups at $T_{24}$, but this may be a too robust outcome measure within such a short period of time and longer term improvements in overall organ function may require a series of treatments. Regarding the length and number of treatments and indicators for terminating extracorporeal cytokine adsorption therapy are very important questions to be answered in the future.

Mortality was $50 \%$ in both groups, however it wasn't the aim to show the effect of one single treatment on survival. Nevertheless, it may be important to note, that although patients looked more severe in the CytoSorb group, they all survived the $48 \mathrm{~h}$ of the study, while 2 patients died in the Control arm before reaching the $48 \mathrm{~h}$.

One of the most important effects of extracorporeal cytokine removal treatment observed in the current study was the significant reduction in the need for vasopressor support, while in the Control group this change could was not shown. This finding was also supported by the measured SVRI values. Although the difference between the groups did not reach statistical significance, these results at least provide some physiological background that vasodilatation, most likely due to the overwhelming effects of pro-inflammatory cytokines, was better controlled in the treated group. This finding is in accordance with previously reported data, both in case series and in recent clinical studies [25]. It is also important to note, that the most profound effects were observed during the first $12 \mathrm{~h}$ of treatment, which has not been reported before.

\subsection{Effects on biomarkers}

There is a broad array of cytokines and biomarkers that can be measured. However, in clinical practice there are only one or two that are used routinely. Our choices were PCT and CRP, as these are measured in our everyday practice.

The adsorption spectrum of the capsule is between 5 and $60 \mathrm{kDa}$ [13]. Besides the reduction in vasopressor requirement, the most significant effect of cytokine adsorption therapy compared to Controls was on PCT concentrations. Procalcitonin has a molecular weight of $13 \mathrm{kDa}$, hence CytoSorb may adsorb PCT directly. Indeed, as hypothesized, in the treatment group there was a significant decrease in PCT concentrations during the first $24 \mathrm{~h}$, which was not observed in the Control group. By $\mathrm{T}_{48}$ PCT decreased significantly in both groups, a pattern that has been observed in several studies when standard treatment is effective [26]. In a previous pilot study, where we measured PCT simultaneously before and after the cartridge, we reported that PCT is directly adsorbed by CytoSorb, and the adsorption is most effective during the first $12 \mathrm{~h}$ of treatment [27]. This explains why the PCT decrease was more pronounced in the CytoSorb group in the current study. This may also explain in part, why the norepinephrine requirement was reduced within the same time frame of $12 \mathrm{~h}$ after the commencement of extracorporeal cytokine adsorption therapy. These results suggest, that changing the adsorber after $12 \mathrm{~h}$ may prove to be beneficial, but this should be tested in the future. This is further supported by the finding, that after the discontinuation of extracorporeal cytokine adsorption therapy, PCT and norepinephrine tended to increase, although this change was not significant. These results also suggest, that the PCT kinetics that we have previously described to predict antibiotic appropriateness [30], cannot be applied during extracorporeal cytokine adsorption treatment.

Nevertheless, the pathophysiological role of PCT in sepsis is not yet fully elucidated. PCT may be an important biomarker that indicates cytokine storm [28], but may also be a toxic mediator in sepsis [29]. The results of this experimental study found that pre-treating animals with anti-PCT antigens, before infecting them with E-coli, improved mortality dramatically while all untreated animals died [29]. In the current study the decreasing PCT concentration was associated with improved clinical parameters such as lower vasopressor need and improved oxygenation. This is in accordance with our previous findings, that PCT kinetics significantly, and within a matter of $12-24 \mathrm{~h}$, separated patients who received appropriate antibiotics compared to those who were administered inappropriate antibiotics, which was also reflected in better clinical outcomes [26].

This observation of significantly reduced PCT concentrations somewhat contradict the results of a recently published clinical trial on extracorporeal cytokine adsorption therapy, in which the primary outcome was change in normalized IL- 6-serum concentrations during study days 1 and 7, but which found no significant difference compared to controls [30]. However, in this study the authors used a different approach (6-h treatment daily), the patient population was also different, and they did not report on PCT concentrations or on norepinephrine requirements.

Extracorporeal cytokine adsorption therapy did not influence CRP concentration in our study. One of the reasons could be that although CRP as a monomer has a molecular weight of around $25 \mathrm{kDa}$, it is usually present as a pentamer, hence cannot be adsorbed by CytoSorb as efficiently as PCT. Furthermore, since CRP has a relatively long half-life and follows the inflammatory process with about $48 \mathrm{~h}$ delay, its use in monitoring the disease progress or treatment efficacy within a short period of time (12-24 h) may be limited [31].

In our study the natural precursor of endothelin-1, BigET-1 (4.2 kDa), decreased significantly in the CytoSorb group between $\mathrm{T}_{0}$ and $\mathrm{T}_{12}, \mathrm{~T}_{24}$. Previously BigET -1 was found to be markedly elevated in patients with severe sepsis compared to healthy volunteers, and its higher concentrations were in correlation with increased serum IL-6, IL-8 concentration and renal failure [32]. Our results are in accordance with these findings and hypothesize that there may be a link between the observed reduced BigET-1 concentrations and the higher SVRI and reduced norepinephrine requirement. Nevertheless, this should be investigated further.

\subsection{Limitations}

This study has several limitations. First of all, the sample size is far too small to draw any firm conclusions regarding treatment effect on organ function or outcome. Furthermore, our findings may not be generalizable to other institutions with different patient populations or clinical practices, and do not provide any data on long term adverse events (i.e.: safety) and outcome. Power analysis was not performed due to the lack of similarly designed studies with such strict criteria set to obtain a relatively homogenous group of patients. By reason of the diversity of septic shock patients, it took us $>2$ years to include 20 out of 716 screened subjects. Furthermore, despite all efforts heterogeneity was 
still present as indicated by the huge scatter of biomarker concentrations and patients seemed to be sicker in the CytoSorb group.

It would have been desirable to measure an array of cytokines, preferably before and after the adsorber, but due to technical difficulties and financial limitations this could not be achieved.

\section{Conclusions}

To our best knowledge, this is the first study, in which extracorporeal cytokine adsorption treatment was tested on its own, and not combined with other extracorporeal renal replacement therapies in a controlled trial. In this proof of concept pilot study, extracorporeal cytokine removal was applied for $24 \mathrm{~h}$ in the early stage of septic shock. The treatment proved to be safe, and we also found that one single treatment already showed some benefits as indicated by reductions in norepinephrine requirements, serum PCT and BigET-1 compared to Controls. These results may provide important support and guidance to future protocol designs and can help to define the appropriate study end points and sample size calculations of clinical trials that aim to investigate the effects of cytokine removal in patients with septic shock.

\section{Ethics approval and consent to participate}

The study protocol was approved by the Regional and Institutional Human Medical Biological Research Ethics Committee, University of Szeged, Hungary (Approval number: SZTESZAKKREG.KUTETIKA 199/ 2016-SZTE). The study was registered on ClinicalTrials.gov, under the registration number of NCT02288975 (registered 13 November 2014) and has been performed in accordance with the ethical standards laid down in the 1964 Declaration of Helsinki and its later amendments. Written informed consent was obtained from all subjects or from their relatives.

\section{Consent for publication}

No individual participant data are reported that would require consent from the participant (or legal parent or guardian for children) to publish.

\section{Availability of data and materials}

The datasets used and/or analyzed during the current study are available from the corresponding author on reasonable request.

\section{Competing interests}

Zsolt Molnar receives honoraria for lecturing and consulting for Pulsion-Maquet, ThermoFisher Scientific, Biotest and CytoSorbents. All the other authors have no conflict of interest.

\section{Funding}

Supported by research grants from the National Research Development and Innovation Office, NKFI 116689, the UNKP-17-4 New National Excellence Program of the Ministry of Human Capacities, "Stay Alive" GINOP-2.3.2.-15-2016-00048 and "Live Longer" EFOP-3.6.2-16-201700006.

\section{Authors' contributions}

ZM and DT conceived the design of the study. FH was the primary author and editor of the manuscript. ZM was the principal investigator for the ACESS trial. FH, IL, NÖ, DT, collected the study data and contributed to the evaluation and interpretation of data and writing and editing of all drafts of the manuscript. FH, IL and DT performed and ZM assisted in, and supervised, the statistical analysis of data. All authors critically reviewed and approved the final manuscript.

\section{Acknowledgements}

Not applicable.

\section{References}

[1] Sogayar AMC, Machado FR, Rea-Neto A, Dornas A, Grion CMC, Lobo SMA, et al. A multicentre, prospective study to evaluate costs of septic patients in Brazilian intensive care units. Pharmacoeconomics 2008;26:425-34. https://doi.org/10.2165/ 00019053-200826050-00006.

[2] Adrie C, Alberti C, Chaix-Couturier C, Azoulay É, De Lassence A, Cohen Y, et al. Epidemiology and economic evaluation of severe sepsis in France: Age, severity, infection site, and place of acquisition (community, hospital, or intensive care unit) as determinants of workload and cost. J Crit Care 2005;20:46-58. https://doi.org/10.1016/j. jcrc.2004.10.005.

[3] Khwannimit B, Bhurayanontachai R. The direct costs of intensive care management and risk factors for financial burden of patients with severe sepsis and septic shock. J Crit Care 2015;30:929-34. https://doi.org/10.1016/j.jcrc.2015.05.011.

[4] Iskander KN, Osuchowski MF, Stearns-Kurosawa DJ, Kurosawa S, Stepien D, Valentine C, et al. Sepsis: multiple abnormalities, heterogeneous responses, and evolving understanding. Physiol Rev 2013;93:1247-88. https://doi.org/10.1152/ physrev.00037.2012.

[5] Kwan A, Hubank M, Rashid A, Klein N, Peters MJ. Transcriptional instability during evolving sepsis may limit biomarker based risk stratification. PLoS One 2013;8: 1-8. https://doi.org/10.1371/journal.pone.0060501.

[6] Akira S, Uematsu S, Takeuchi O. Pathogen recognition and innate immunity. Cell 2006;124:783-801. https://doi.org/10.1016/j.cell.2006.02.015.

[7] Hotchkiss RS, Monneret G, Payen D. Sepsis-induced immunosuppression: From cellular dysfunctions to immunotherapy. Nat Rev Immunol 2013;13:862-74. https:// doi.org/10.1038/nri3552.

[8] Venet F, Lukaszewicz AC, Payen D, Hotchkiss R, Monneret G. Monitoring the immune response in sepsis: A rational approach to administration of immunoadjuvant therapies. Curr Opin Immunol 2013;25:477-83. https://doi.org/10.1016/j.coi.2013. 05.006.

[9] László I, Trásy D, Molnár Z, Fazakas J. Sepsis: from pathophysiology to individualized patient care. J Immunol Res 2015;2015. https://doi.org/10.1155/2015/510436.

[10] Cruz DN, Antonelli M, Fumagalli R, Foltran F, Brienza N, Donati A, et al. Early use of polymyxin B hemoperfusion in abdominal septic shock. JAMA 2009;301:2445. https://doi.org/10.1001/jama.2009.856.

[11] Kreymann KG, De Heer G, Nierhaus A, Kluge S. Use of polyclonal immunoglobulins as adjunctive therapy for sepsis or septic shock. Crit Care Med 2007;35:2677-85. https://doi.org/10.1097/01.CCM.0000295263.12774.97.

[12] Bellomo R, Baldwin I, Ronco C. Extracorporeal blood purification therapy for sepsis and systemic inflammation: its biological rationale. Contrib Nephrol 2001;132: 367-74. https://doi.org/10.1159/000060105.

[13] Cytosorbents. The Adsorber n.d. http://cytosorb-therapy.com/the-adsorber (accessed March 5, 2018).

[14] Namas R, Namas R. Hemoadsorption Reprograms Inflammation in Experimental Gram-negative Septic Peritonitis: Insights from In Vivo and In Silico Studies. Mol Med 2012;18:1. https://doi.org/10.2119/molmed.2012.00106.

[15] Peng Z-Y, Carter MJ, Kellum JA. Effects of hemoadsorption on cytokine removal and short-term survival in septic rats. Crit Care Med 2008;36:1573-7. https://doi.org/10. 3174/ajnr.A1256.Functional.

[16] Peng ZY, Wang HZ, Carter MJ, Dileo MV, Bishop JV, Zhou FH, et al. Acute removal of common sepsis mediators does not explain the effects of extracorporeal blood purification in experimental sepsis. Kidney Int 2012;81:363-9. https://doi.org/10.1038/ ki.2011.320.

[17] Kellum JA, Venkataraman R, Powner D, Elder M, Hergenroeder G, Carter M. Feasibility study of cytokine removal by hemoadsorption in brain-dead humans. Crit Care Med 2008;36:268-72. https://doi.org/10.1097/01.CCM.0000291646.34815.BB.

[18] Friesecke S, Träger K, Schittek GA, Molnar Z, Bach F, Kogelmann K, et al. International registry on the use of the CytoSorb ${ }^{\circledR}$ adsorber in ICU patients: Study protocol and preliminary results. Medizinische Klin - Intensivmed Und Notfallmedizin 2017; 2017. https://doi.org/10.1007/s00063-017-0342-5.

[19] Rhodes A, Evans LE, Alhazzani W, Levy MM, Antonelli M, Ferrer R, et al. Surviving Sepsis Campaign: International Guidelines for Management of Sepsis and Septic Shock. , vol. 43Berlin Heidelberg: Springer; 2016. https://doi.org/10.1007/s00134017-4683-6.

[20] Moreno R, Vincent JL, Matos R, Mendonça A, Cantraine F, Thijs L, et al. The use of maximum SOFA score to quantify organ dysfunction/failure in intensive care. Results of a prospective, multicentre study. Intensive Care Med 1999;25:686-96. https://doi.org/10.1007/s001340050931.

[21] Hetz H, Berger R, Recknagel P, Steltzer H. Septic shock secondary to $\beta$-hemolytic streptococcus-induced necrotizing fasciitis treated with a novel cytokine adsorption therapy. Int J Artif Organs 2014;37:422-6. https://doi.org/10.5301/ijao.5000315.

[22] Kogelmann K, Jarczak D, Scheller M, Drüner M. Hemoadsorption by CytoSorb in septic patients: A case series. Crit Care 2017;21:1-10. https://doi.org/10.1186/s13054017-1662-9.

[23] van der Linde GW, Grootendorst AF. First case of toxic shock treated with haemoadsorption by cytosorb ${ }^{\circledR}$ in the Netherlands. Netherlands J Crit Care 2016; 24:27-9. 
[24] David S, Thamm K, Schmidt BMW, Falk CS, Kielstein JT. Effect of extracorporeal cytokine removal on vascular barrier function in a septic shock patient. J Intensive Care 2017;5:1-5. https://doi.org/10.1186/s40560-017-0208-1.

[25] Nemeth E, Kovacs E, Racz K, Soltesz A, Szigeti S, Kiss N, et al. Impact of intraoperative cytokine adsorption on outcome of patients undergoing orthotopic heart transplantation - an observational study. Clin Transplant 2018. https://doi.org/10.1111/ctr.13211.

[26] Trásy D, Tánczos K, Németh M, Hankovszky P, Lovas A, Mikor A, et al. Early procalcitonin kinetics and appropriateness of empirical antimicrobial therapy in critically ill patients. A prospective observational study. J Crit Care 2016;34:50-5. https://doi.org/10.1016/j.jcrc.2016.04.007.

[27] Öveges N, László I, Forgács M, Kiss T, Hankovszky P, Palágyi P, et al. Procalcitonin elimination during cytokine adsorption therapy in septic shock: a spin-off study of the ACESS trial. Crit Care 2017;21:383. https://doi.org/10.1186/s13054-017-1629-x.

[28] Riedel S. Procalcitonin and the role of biomarkers in the diagnosis and management of sepsis. Diagn Microbiol Infect Dis 2012;73:221-7. https://doi.org/10.1016/j. diagmicrobio.2012.05.002.
[29] Nylen ES, Whang KT, Snider RH, Steinwald PM, White JC, Becker KL. Mortality is increased by procalcitonin and decreased by an antiserum reactive to procalcitonin in experimental sepsis. Crit Care Med 1998;26:1001-6. https://doi.org/10.1097/ 00003246-199806000-00015.

[30] Schädler D, Pausch C, Heise D, Meier-Hellmann A, Brederlau J, Weiler N, et al. The effect of a novel extracorporeal cytokine hemoadsorption device on IL-6 elimination in septic patients: A randomized controlled trial. PLoS One 2017;12:1-19. https://doi. org/10.1371/journal.pone.0187015.

[31] Trásy D, Molnár Z. Procalcitonin - assisted antibiotic strategy in sepsis. EJIFCC 2017; 28:104-13 Retrieved from https://www.ncbi.nlm.nih.gov/pmc/articles/ PMC5460008/pdf/ejifcc-28-104.pdf.

[32] Tschaikowsky K, Sägner S, Lehnert N, Kaul M, Ritter J. Endothelin in septic patients: effects on cardiovascular and renal function and its relationship to proinflammatory cytokines. Crit Care Med 2000;28:1854-60. https://doi.org/10.1097/00003246200006000-00028. 